\title{
PReS-FINAL-2293: An attempt to analyze variants of systemic lupus erythematosus onsets in childhood
}

\author{
E Kuchinskaya*, M Dubko \\ From 20th Pediatric Rheumatology European Society (PReS) Congress \\ Ljubljana, Slovenia. 25-29 September 2013
}

\section{Introduction}

Childhood-onset systemic lupus erythematosus (SLE), compared with adult-onset variants, is characterized by severity, variety of organ involvement, unpredictable history and diversity of onset variants.

\section{Objectives}

To analyze and try to systemize variants of SLE onsets among patients of rheumatology department.

\section{Methods}

We collected and analyzed 27 cases of systemic lupus erythematosus in children (age up to 18 years) admitted to our department from 2006 to 2013.

\section{Results}

Among 27 patients there were 21 (78\%) females and 6 (22\%) males; 11 years was an average age of onset. Variants of SLE onset can be systemized by different ways:

\section{According to time from first manifestation to complete clinical presentation}

«Acute» onset: time from first symptom to complete clinical presentation is less than 1 month - 9\% (14 of 27) Among such cases were $4(14,8 \%)$ with delayed (5-14 months) new organ involvement. 3 patients presented with renal involvement: 2 cases of microhematuria, proteinuria in patients without cytostatic therapy; 1 case of nephrotic syndrome in patient treated by chloroquine. 2 patients (treated by cytostatic drugs) presented with neuropsychiatric manifestations: seizures, focal cortical neurologic signs.

\footnotetext{
Saint-Petersburg State Pediatric Medical University, Saint-Petersburg, Russian
} Federation clinical presentation - from 1 to 3 months - 14,8\% (4 of 27). This variant is characterized by progressive, step-bystep involvement of new organ systems without any regularity in priority.

«Prolonged» onset: slow evolution of clinical manifestations (from 8 to 24 months in this research) $-33,3 \%$ (9 of 27)

\section{According to inflammatory activity of disease onset}

$55 \%$ of 27 patients presented fever (17 of 27 ). In $66 \%$ cases increased ESR/CRP rate was detected. Fever is more common for patients with «acute» or «subacute» onset variant $(61 \%-11$ of 18$)$, all of them also had increased ESR/CRP rate. Fever also presented in 4 patients of 9 «prolonged» onsets (44\%), increased ESR/ CRP rate in 7 of 9 (77\%). Both fever and increased ESR/ CRP rate were detected in different time from onset.

\section{According to primary affected organ system}

Dermatologic manifestation (malar rash, photosensitivity, non-specific rash) was the first symptom for majority of patients $(44 \%-12$ of 27$), 3$ of them had both dermatologic manifestation and oral ulcers. 7 patients $(25,9 \%)$ started their history with different autoimmune cytopenias, including acute haemolytic anemia as the first symptom ( 2 cases), and acute thrombocytopenic purpura (3 cases). Frank arthritis or arthralgia presented in 7 cases $(25,9 \%)$ as single symptom or in combination with another manifestations. 3 cases started with thrombosis as manifestation of antiphospholipid syndrome (later confirmed by laboratory tests). There was 1 case with episodes of severe headaches as single complaint for a long time, 1 case with vein thrombosis of leg; one 
patient with appendicitis and intestinal ulcers (as manifestation of mesenterial vein trombosis). 2 patients had prolonged history (up to 2 years) of non-specific manifestations (fatigue, weakness, weight loss, myalgia) before first clinical symptoms.

\section{Conclusion}

It's hard to systemize onsets of systemic lupus erythematosus because of their variability; and this variability causes variations of disease management and treatment tactics.

\section{Disclosure of interest}

None declared

Published: 5 December 2013

- Convenient online submission

- Thorough peer review

- No space constraints or color figure charges

- Immediate publication on acceptance

- Inclusion in PubMed, CAS, Scopus and Google Scholar

- Research which is freely available for redistribution 